\title{
Model test of new floating offshore wind turbine platforms
}

\author{
Hyunkyoung Shin ${ }^{1}$, Pham Thanh Dam ${ }^{1}$, Kwang Jin Jung ${ }^{1}$ \\ Jinseob Song ${ }^{2}$, Chaewhan Rim $^{2}$ and Taeyoung Chung ${ }^{2}$ \\ ${ }^{I}$ School of Naval Architecture and Ocean Engineering, University of Ulsan, Ulsan, Korea \\ ${ }^{2}$ Korea Institute of Machinery \& Materials, Daejeon, Korea
}

\begin{abstract}
This paper presents the model test results of 3 new spar platforms which were developed based on the OC3-Hywind spar to support a 5-MW wind turbine. By changing the shape but keeping both volume and mass of OC3Hywind spar platform, those platforms were expected to experience different hydrodynamic and hydrostatic loads. The scale models were built with a 1/128 scale ratio. The model tests were carried out in waves, including both rotating rotor effect and mean wind speed. The characteristic motions of the 3 new models were measured; Response Amplitude Operators (RAO) and significant motions were calculated and compared with those of OC3-Hywind.
\end{abstract}

KEY WORDS: 5-MW floating offshore wind turbine; Model test; Response amplitude operator; Significant motion; OC3-Hywind Spar.

\section{INTRODUCTION}

Recently, some concepts of floating offshore wind turbines (FOWT) have been designed and installed in deep sea greater than $50 \mathrm{~m}$, while a large number of bottom-mounted offshore wind turbines have been installed in water depths less than $45 \mathrm{~m}$ supporting 3 5MW RNA. Several researches on FOWTs have been made. Bulder et al. (2002) analyzed a tri-floater platform wind turbine; Lee (2005) studied a 1.5-MW wind turbine; Wayman (2006), Wayman et al. (2006), Sclavounos et al. (2007), Jonkman et al. (2009), Jonkman (2010), Jensen et al. (2011) and Wang and Sweetman (2012) analyzed various TLP, spar, semi-submersible and barge substructures of FOWT.

A concept of spar type FOWT was defined by IEA Task 23 OC3 project to support a 5MW wind turbine based on the prototype Hywind (Jonkman et al., 2009). Scale model tests of OC3-Hywind had been carried out in the Wide Tank of the University of Ulsan (UOU) (Kim, 2011; Shin, 2011). Its results had a good agreement with numerical simulations.

This study focuses on improvement of 5-MW FOWT platforms in deep water. We deploy three new platforms of which both mass and volume remain unchanged in comparison with OC3-Hywind. However, hydrodynamic and hydrostatic loads on platforms vary because the platforms have the ballast plate with a large diameter at the bottom and the ring cylinders at the top side of platform.

\section{NEW PLATFORMS}

Three new platforms are called M1, M2 and M3, respectively and are shown in Fig. 1. Table 1 and Table 2 show general and different properties of three new platforms, respectively. Both mass and volume of platforms keep the same as those of OC3-Hywind. The shapes are different from each other, depending on the position of ring cylinders around the main structure.

The ring cylinder of M1 was located $12 \mathrm{~m}$ below mean sea level (MSL). The main cylinder diameter is $6.5 \mathrm{~m}$, the ring cylinder

Corresponding author: Hyunkyoung Shin

e-mail:hkshin@ulsan.ac.kr 
diameter is $17 \mathrm{~m}$, and the ballast plate diameter is $18 \mathrm{~m}$. The center of buoyancy (COB) of M1 is higher than that of OC3-Hywind because of the ring cylinder at high position. The roll and pitch inertia of M1 are twice higher than those of OC3-Hywind because of the bottom ballast plate filled with concrete inside. M2 has lower position of ring cylinder than M1. The distance from MSL to the ring cylinder is $27 \mathrm{~m}$. It means that M2 has lower position of COB. The distance from MSL to the ring cylinder of M3 is $42 \mathrm{~m}$. The COB of M3 is lower than those of both M1 and M2. The center of gravity (COG), roll and pitch inertia of M3 are also smaller than those of both M1 and M2. Table 2 shows the difference in COB, COG and inertia of M1 M3.

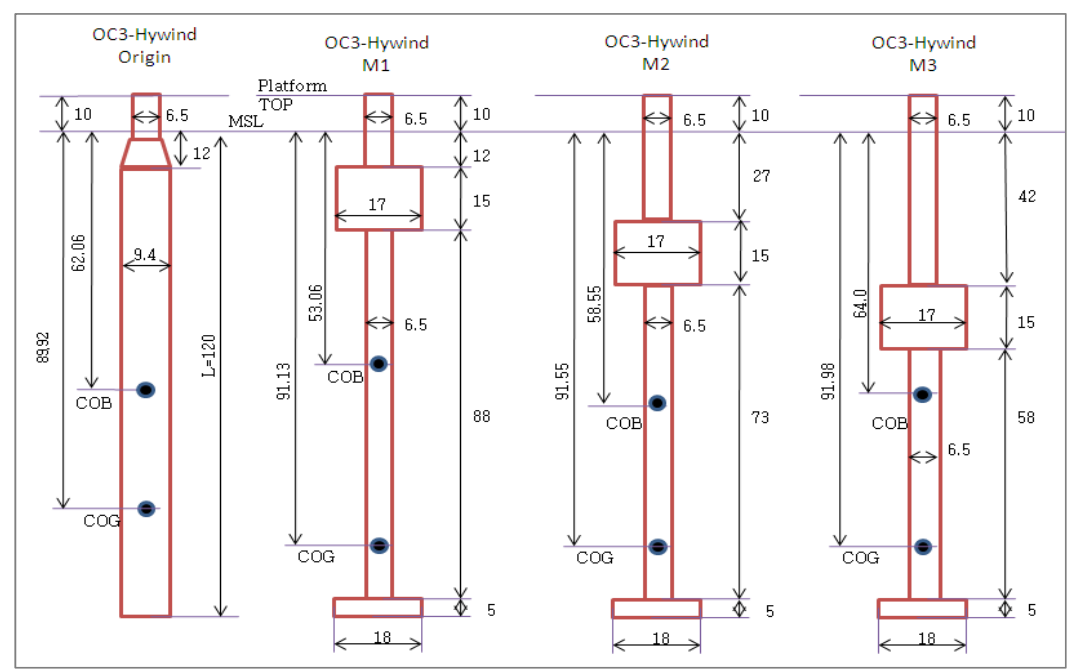

Fig. 1 Three new platforms in comparison with OC3-Hywind spar (unit $=m$ ).

Table 1 General properties of three new platforms M1, M2 and M3.

\begin{tabular}{|c|c|c|c|}
\hline Index & Unit & Full-scale & Model (1:128) \\
\hline Water depth & $m$ & 320 & 2.5 \\
\hline Rotor mass (included blade mass) & $\mathrm{kg}$ & 110,000 & 0.0525 \\
\hline Rotor diameter & $m$ & 126 & 0.984 \\
\hline Number of blades & & 3 & 3 \\
\hline Nacelle mass & $\mathrm{kg}$ & 240,000 & 0.1144 \\
\hline Tower length & $m$ & 77.6 & 0.6063 \\
\hline Tower mass & $\mathrm{kg}$ & 249,718 & 0.12 \\
\hline Tower top diameter & $m$ & 3.87 & 0.0302 \\
\hline Tower base diameter & $m$ & 6.5 & 0.051 \\
\hline Platform length & $m$ & 130 & 1.016 \\
\hline Platform mass & $k g$ & 7466330 & 3.5 \\
\hline Total tension at fairleads & $N$ & $1,606,417$ & 0.766 \\
\hline Number of mooring line & & 3 & 3 \\
\hline Unstretched mooring line length & $m$ & 902.2 & 7.048 \\
\hline Mooring line diameter & $m$ & 0.09 & 0.001 \\
\hline Anchor/fairlead radius from platform centerline & $m$ & $853.87 / 5.2$ & $6.671 / 0.041$ \\
\hline Equivalent mooring line mass density & $\mathrm{kg} / \mathrm{m}$ & 77.7066 & $3.80 \mathrm{E}-05$ \\
\hline Equivalent mooring line extensional stiffness & $k N$ & 384,243 & - \\
\hline Depth to fairlead from MSL & $m$ & 70 & 0.546875 \\
\hline
\end{tabular}


Table 2 Different properties of three new platforms M1, M2 and M3.

Scale $=1: 128$

\begin{tabular}{|l|c|c|c|c|}
\hline \multicolumn{1}{|c|}{ Properties } & Full-scale & M1 & M2 & M3 \\
\hline Center of buoyancy $(m)$ & -53.057 & -0.415 & -0.457 & -0.500 \\
\hline Center of mass $(m)$ & -91.13 & -0.712 & -0.715 & -0.719 \\
\hline Roll inertia $\left(\mathrm{kg} \mathrm{m}^{2}\right)$ & $8.53 \mathrm{E}+09$ & $2.48 \mathrm{E}-01$ & $2.37 \mathrm{E}-01$ & $2.28 \mathrm{E}-01$ \\
\hline Pitch inertia $\left(\mathrm{kg} \mathrm{m}^{2}\right)$ & $8.53 \mathrm{E}+09$ & $2.48 \mathrm{E}-01$ & $2.37 \mathrm{E}-01$ & $2.28 \mathrm{E}-01$ \\
\hline Yaw inertia $\left(\mathrm{kg} \mathrm{m}^{2}\right)$ & $1.86 \mathrm{E}+08$ & $5.41 \mathrm{E}-03$ & $5.41 \mathrm{E}-03$ & $5.41 \mathrm{E}-03$ \\
\hline
\end{tabular}

The mooring system includes 3 mooring lines; the fairleads are located at a depth of $70.0 \mathrm{~m}$ below the SWL and at a radius of $5.2 \mathrm{~m}$ from the platform centerline. One of the lines is directed nominally upwind along the positive X-axis (in the XZ-plane). The two remaining lines are distributed uniformly around the platform, such that each line, fairlead, and anchor is $120^{\circ}$ apart.

\section{MODEL TEST}

The scale model tests of 3 new platforms were carried out at the Ocean Engineering Wide Tank, UOU which is $30 \mathrm{~m}$ in length, $20 \mathrm{~m}$ in width and $2.5 \mathrm{~m}$ in water depth (Fig. 2) in order to evaluate motion characteristics in combined wind/wave conditions. RAOs and significant motions were calculated from measured data and compared with those of OC3-Hywind.

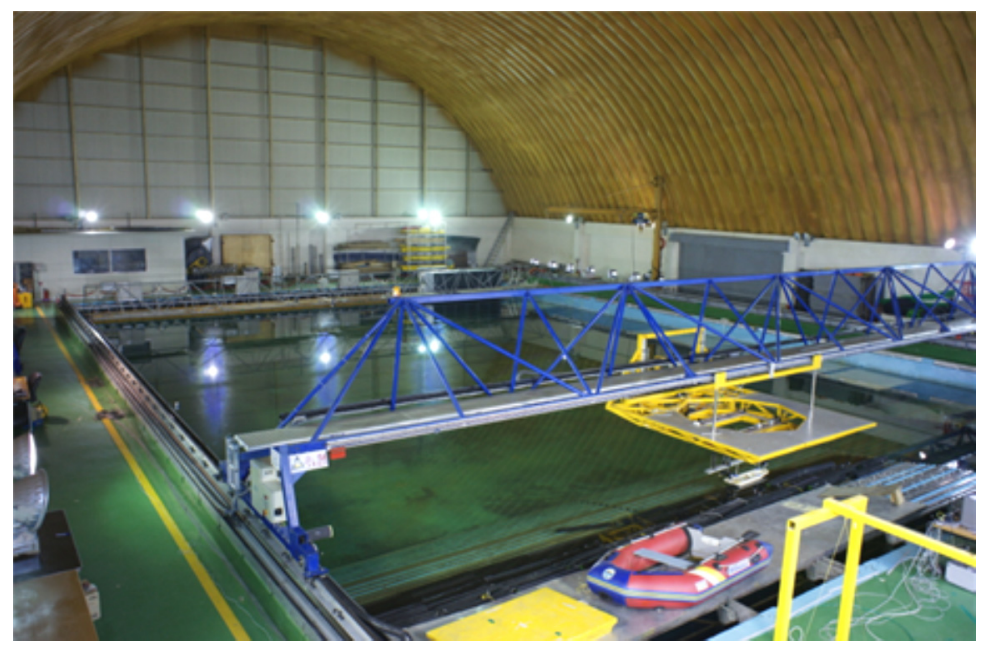

Fig. 2 Ocean engineering wide tank, UOU.

\section{Model}

The geometric model scale ratio is $\lambda=1: 128$ and the scaling factors were determined according to Froude's law of similarity shown in Table 3. The rotor, nacelle, tower and mooring system were the same as those used in the model tests of OC3-Hywind spar.

\section{Facilities}

The wide tank has a multi-directional wave maker system and a wind generator system in Fig. 3. Wavemaker can produce regular waves and irregular waves (ISSC, JONSWAP, Scott, ITTC, Neumann, Pierson-Moskowitz, etc.). The model was set at $15 \mathrm{~m}$ downstream of the wave generator as shown in Figs. 3 and 4. A wave probe was placed to measure the wave elevation. Four passive makers were mounted on the tower of the model to measure motions in six degrees of freedom by means of eight 
Vicon cameras. Test data was recorded in $100 \mathrm{~s}$ with the sampling frequency of $100 \mathrm{~Hz}$. Three tension meters were mounted at anchor positions to check the tension in each mooring line.

Table 3 Scaling factors for floating wind turbine model testing.

\begin{tabular}{|l|c|c|}
\hline \multicolumn{1}{|c|}{ Parameter } & Unit $(s)$ & Scale factor \\
\hline Length (including wave height ...) & $L$ & $\lambda^{2}$ \\
\hline Area & $L^{2}$ & $\lambda^{3}$ \\
\hline Volume & $L^{3}$ & 1 \\
\hline Density & $M / L^{3}$ & $\lambda^{3}$ \\
\hline Mass & $M$ & $\lambda^{0.5}$ \\
\hline Time & $T$ & $\lambda^{-0.5}$ \\
\hline Frequency (rotor rotational speed) & $1 / T^{l}$ & $\lambda^{0.5}$ \\
\hline Velocity (wind speed, wave celerity) & $L T^{-1}$ & $\lambda^{3}$ \\
\hline Force (wind, wave) & $M L / T^{2}$ & $\lambda^{5}$ \\
\hline Mass moment of inertia & $M L^{2}$ & \\
\hline
\end{tabular}

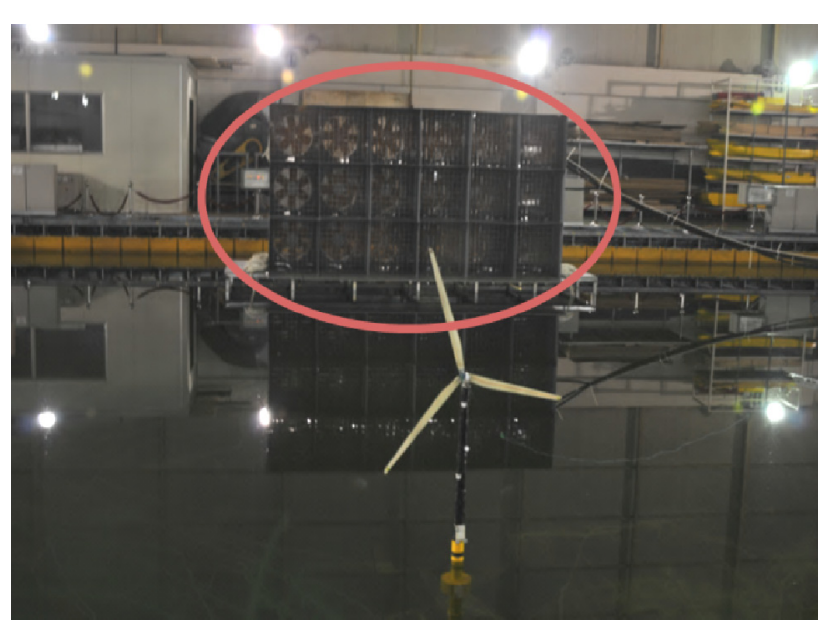

Fig. 3 Wind generator and wave maker.

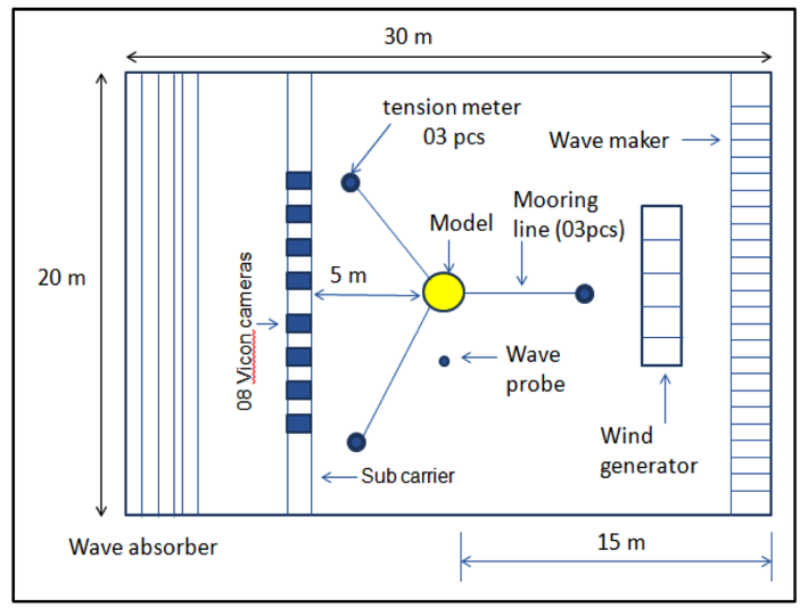

Fig. 4 Model test arrangement.

\section{Wind generator}

The wind generator in Fig. 3 is composed of eighteen fans and is used to create wind load acting on offshore wind turbines in scale model test. It can generate both steady wind and unsteady wind. Maximum wind speed is about $10 \mathrm{~m} / \mathrm{s}$. The wind speed can be controlled by computer software (Labview).

\section{Measuring equipment (Sensor)}

Wave probes, anemometers, RPM measurement device, water-proof tension meter, VICON cameras and passive markers are employed in order to measure wind, wave, rotor revolution, tension and motion, respectively.

\section{Wave probe and anemometers}

Wave probes and anemometers in Fig. 5 are calibrated using a height gage and in the UOU Wind Tunnel, respectively. 

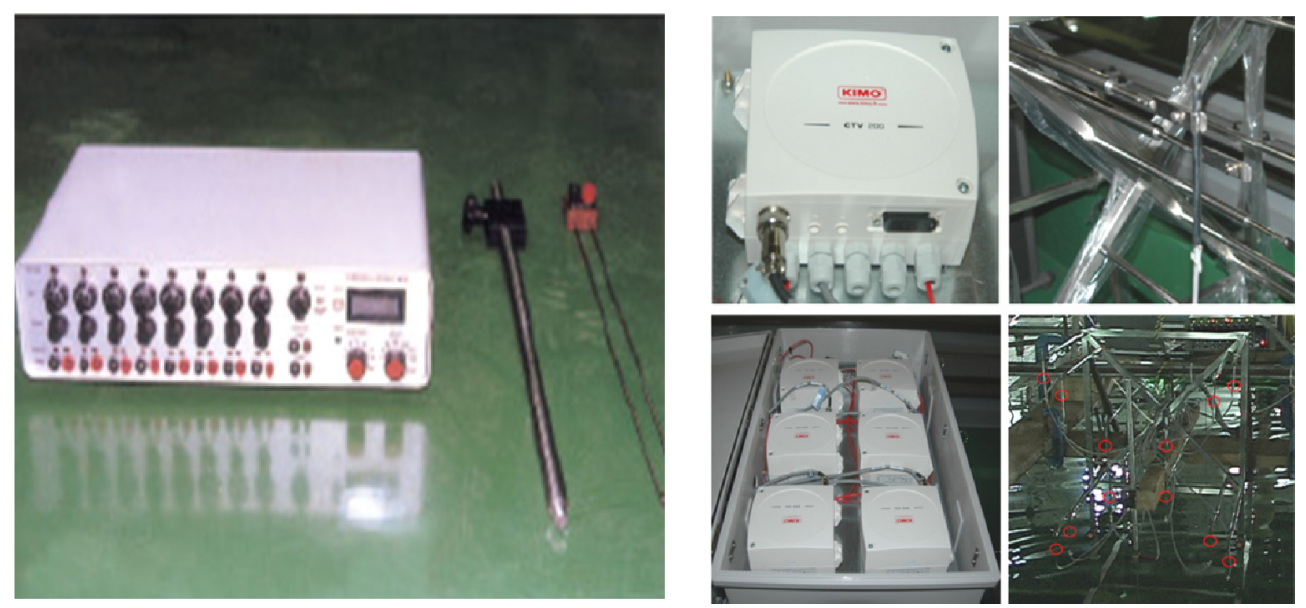

Fig. 5 Wave probe and anemometer.

\section{Tension meter}

Tension meter is used to measure the tensile forces acting on mooring lines.

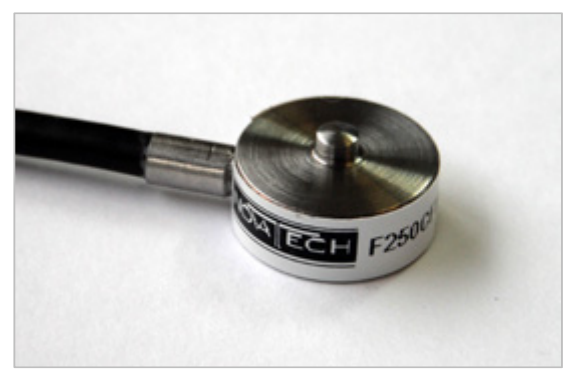

Fig. 6 Tension meter.

\section{VICON camera and passive marker}

VICON cameras measure the motion of structure as perceiving the infrared ray reflected from passive marker (Fig. 7). At least three markers are needed to measure the motion and they have to be stuck on the structure with distance $0.1 \sim 0.15 \mathrm{~m}$.
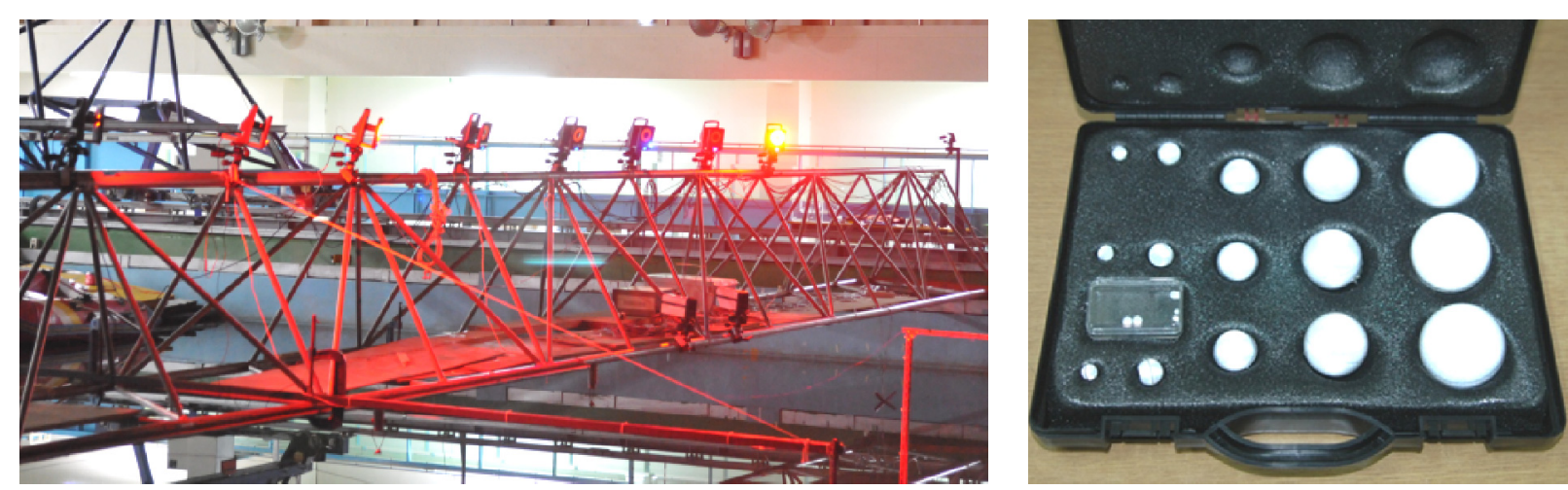

Fig. 7 Vicon cameras and passive markers.

\section{Load case}

The 5MW offshore wind turbines in full scale operate with rotor speed $12.1 \mathrm{rpm}$ at mean wind speed $11.4 \mathrm{~m} / \mathrm{s}$. Both rotor speed and mean wind speed are Froude scaled as follows (Table 3) : 
Rotor speed $=136.9 \mathrm{rpm}$, Mean wind speed $=1.007 \mathrm{~m} / \mathrm{s}$

Load cases in the model test are defined as follows:

- LC01: Regular waves, no wind, parked rotor.

- LC02: Regular waves, mean wind speed, parked rotor.

- LC03: Regular waves, mean wind speed and rotating rotor.

- LC04: Irregular wave, no wind, parked rotor.

- LC05: Irregular waves, mean wind speed, parked rotor.

- LC06: Irregular waves, mean wind speed, rotating rotor.

Table 4 Regular waves.

\begin{tabular}{|c|c|c|c|c|}
\hline \multicolumn{2}{|c|}{ Full scale } & \multicolumn{2}{c|}{ Model } \\
\hline No & \multicolumn{2}{|c|}{ Tegular wave $(s)$} & 0.619 \\
\hline 1 & $\mathrm{~T}(s)$ & $\mathrm{H}(m)$ & 1.061 & 0.02 \\
\hline 2 & 7.00 & 2.56 & 0.833 & 0.02 \\
\hline 3 & 9.42 & 2.56 & 0.884 & 0.02 \\
\hline 4 & 10.00 & 2.56 & 1.237 & 0.02 \\
\hline 5 & 12.00 & 2.56 & 1.503 & 0.02 \\
\hline 6 & 14.00 & 2.56 & 1.856 & 0.02 \\
\hline 7 & 17.00 & 2.56 & 2.121 & 0.02 \\
\hline 8 & 21.00 & 2.56 & 2.298 & 0.02 \\
\hline 9 & 24.00 & 2.56 & 2.475 & 0.02 \\
\hline 10 & 26.00 & 2.56 & 2.562 & 0.02 \\
\hline 11 & 28.00 & 2.56 & 3.005 & 0.02 \\
\hline 13 & 30.00 & 2.56 & & 0.02 \\
\hline
\end{tabular}

Table 5 Irregular waves.

\begin{tabular}{|c|c|c|c|c|c|}
\hline \multicolumn{7}{|c|}{ Irregular wave } \\
\hline & \multicolumn{3}{|c|}{ Full scale model } & $\mathrm{T}_{\mathrm{P}}(s)$ & $\mathrm{H}_{\mathrm{S}}(\mathrm{m})$ \\
\hline No & Sea state & $\mathrm{T}_{\mathrm{P}}(s)$ & $\mathrm{H}_{\mathrm{S}}(m)$ & 0.857 & 0.029 \\
\hline 1 & 5 & 9.7 & 3.66 & 0.999 & 0.043 \\
\hline 3 & 6 & 11.3 & 5.49 & 1.202 & 0.071 \\
\hline 4 & 7 & 13.6 & 9.14 & 1.503 & 0.119 \\
\hline
\end{tabular}

\section{RESULTS AND COMPARISONS}

\section{Response Amplitude Operator (RAO)}

LC01 : Regular waves, no wind, parked rotor

In surge, heave and pitch, responses of M1and M3 are smaller than those of the original while M2 in surge and pitch shows 
peak values much higher than those of the original (Figs. 8 and 9).
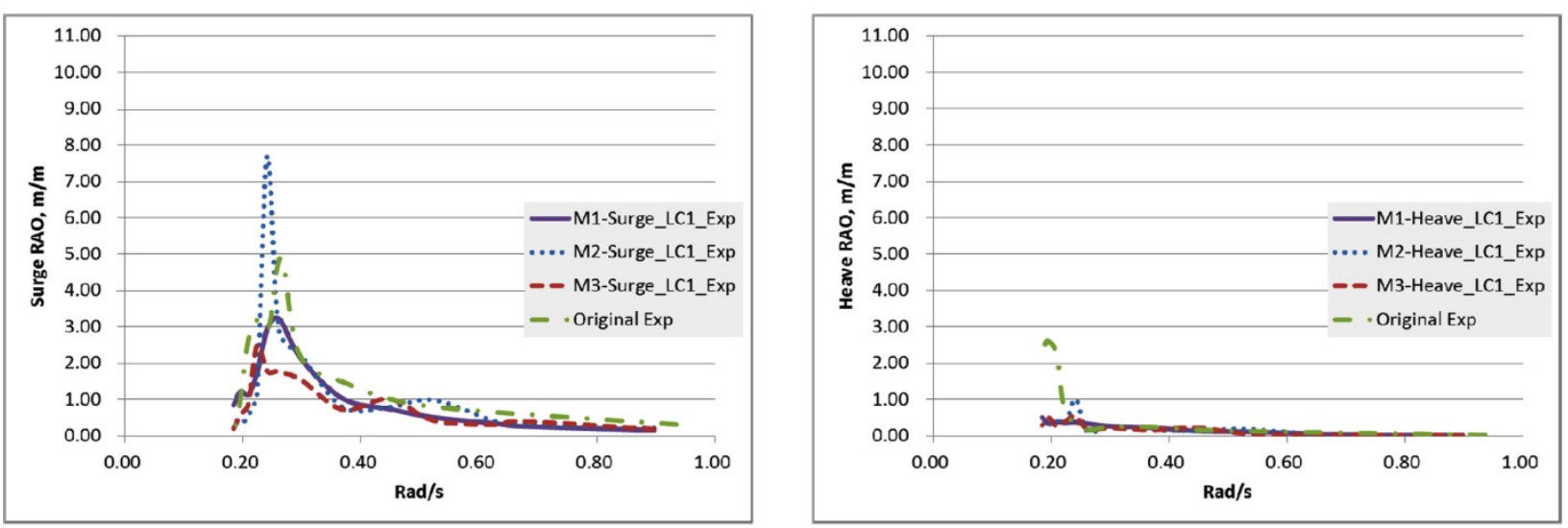

Fig. 8 Surge, heave RAOs in LC01.
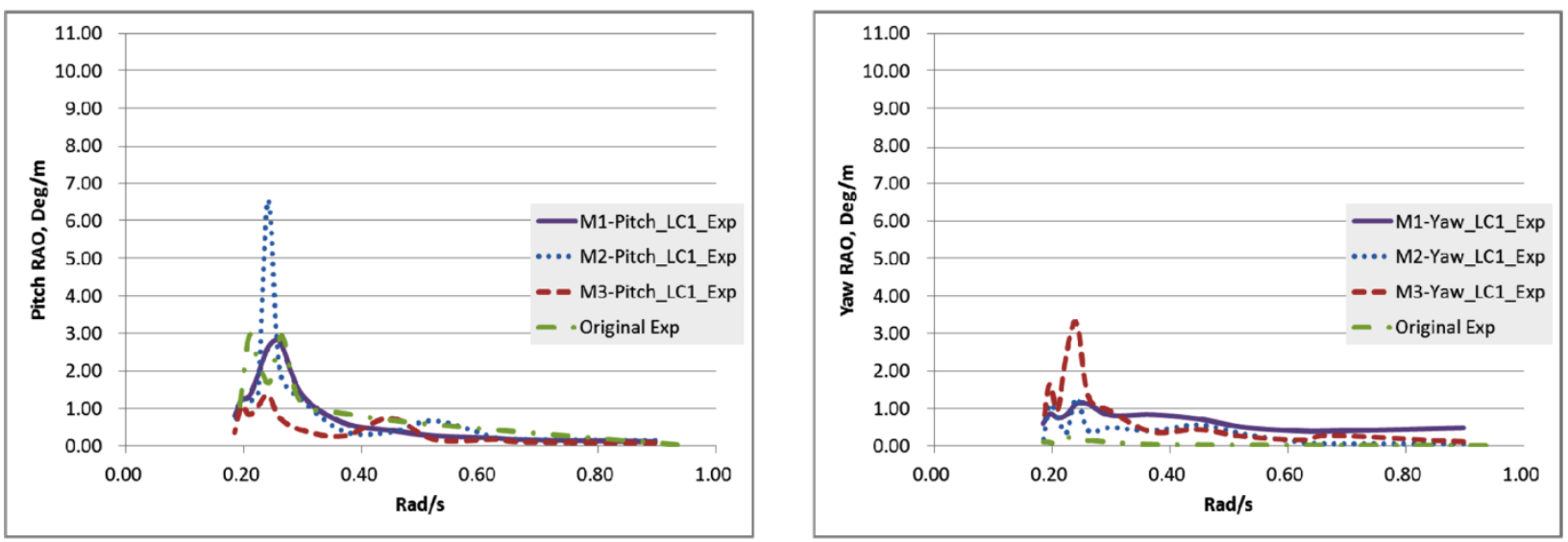

Fig. 9 Pitch and yaw RAOs in LC01.

\section{LC02 : Regular waves, mean wind speed, parked rotor}

As in LC01, in surge, heave and pitch, responses of M1and M3 are smaller than those of the original while M2 in surge and pitch shows peak values much higher than those of the original (Figs. 10 and 11). The large yaw angle of the original OC3 Hywind may result from no crow-foot delta mooring which was designed for additional yaw stiffness in the full scale of original.
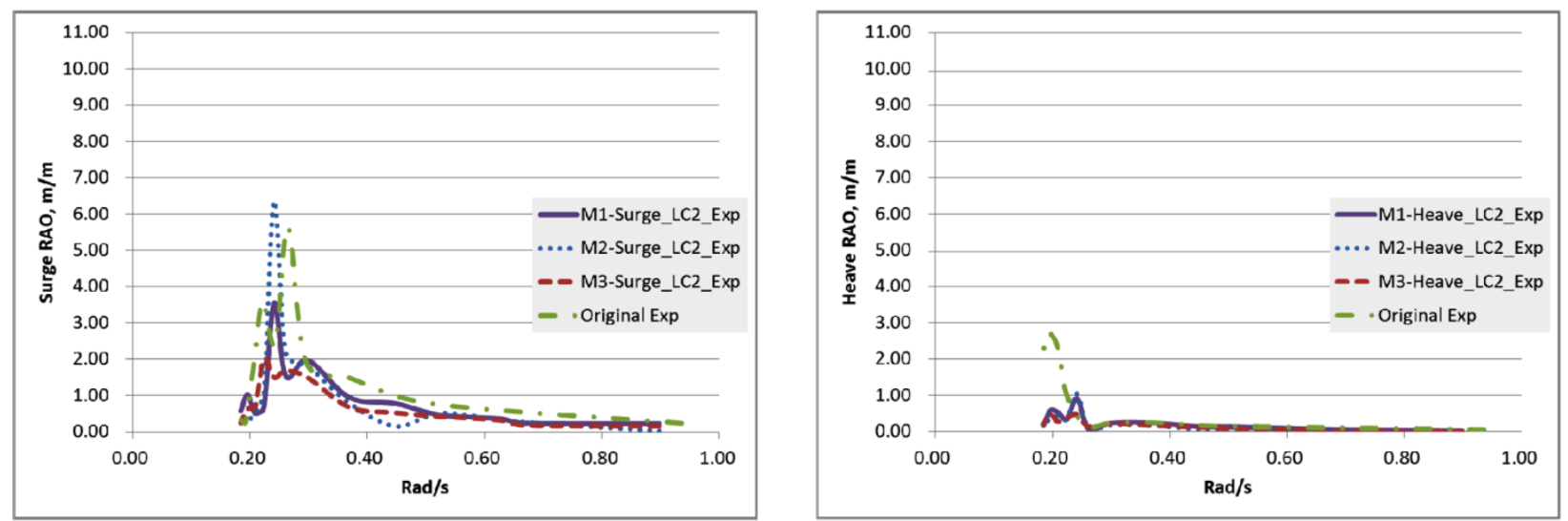

Fig. 10 Surge, heave RAOs in LC02. 

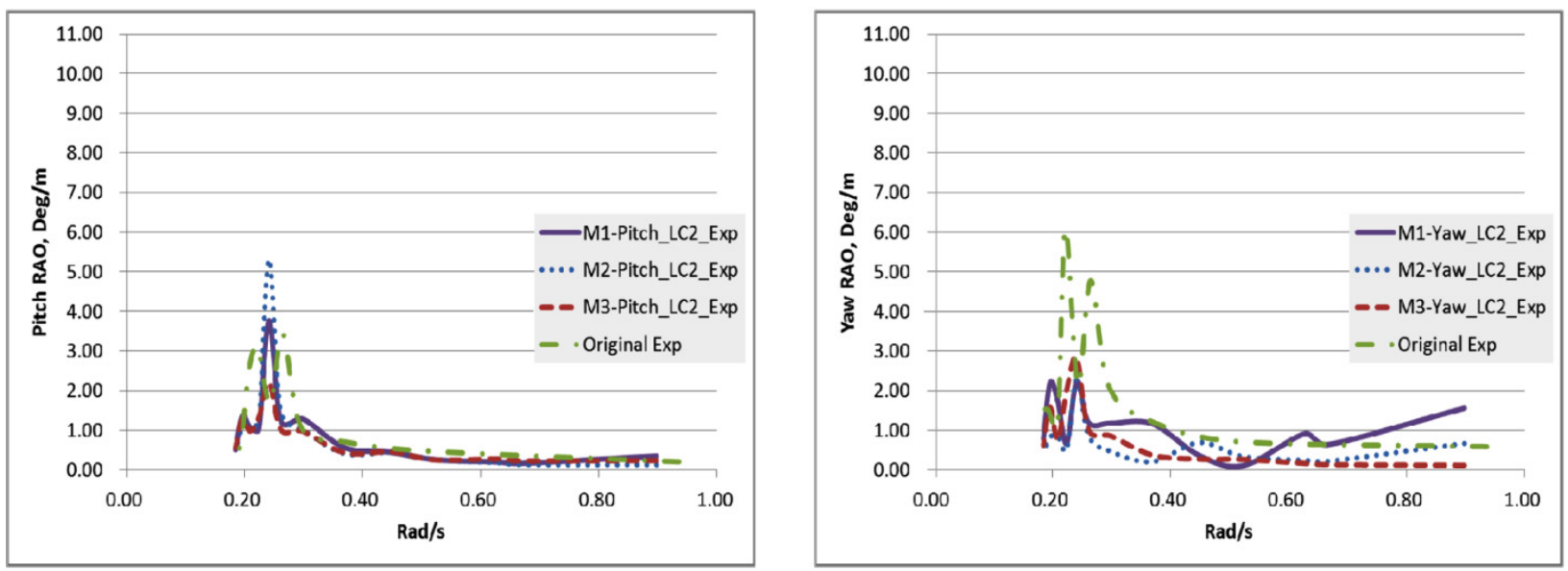

Fig. 11 Pitch and yaw RAOs in LC02.

LC03 : Regular waves, mean wind speed and rotating rotor

In every mode, M3 shows smaller responses than M1, M2 and the original under the combined environmental condition including rotor rotation effect (Figs. 12 and 13). In LC01 LC03 with regular waves, M3 shows the best performance. Heave RAO of all models are similar but difference in peak value.
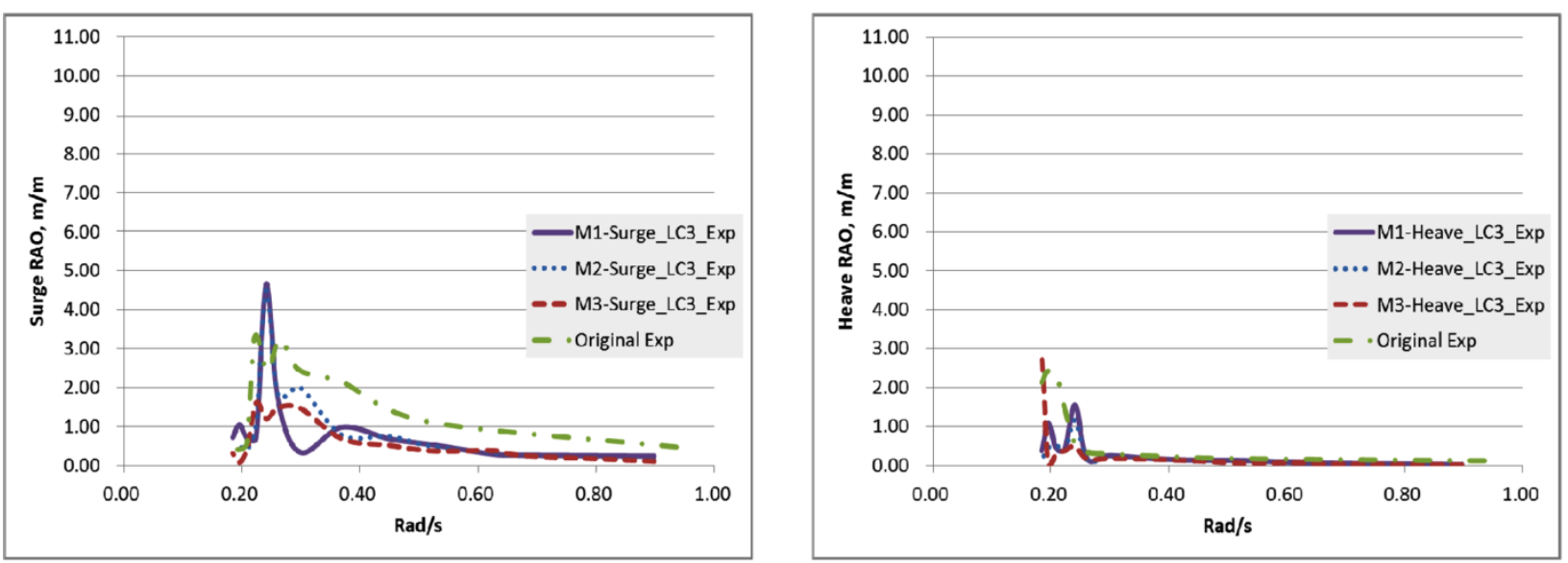

Fig. 12 Surge, heave RAOs of LC03.
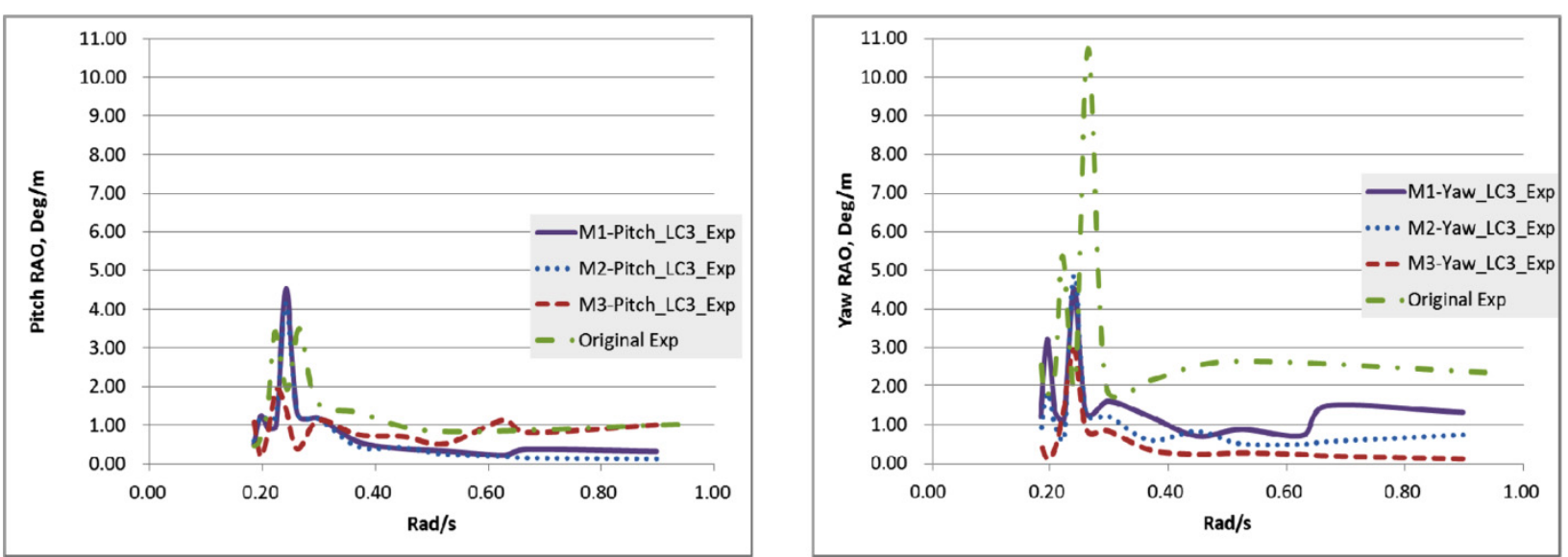

Fig. 13 Pitch and yaw RAOs of LC03. 


\section{Significant response}

The behavior of floating offshore wind turbines in irregular waves is expressed in terms of significant height of motion responses at specified sea states. Model tests were carried out in sea states 5 8.

\section{LC04 : Irregular wave, no wind, parked rotor}

In surge, significant motions of M1 M3 are smaller than those of the original. In heave, significant motions of all models are similar to each other. In pitch, M2 in irregular waves shows the smallest significant motion in contrast to regular waves. In yaw M3 shows the smallest response. M3 shows the smallest responses in all modes except in pitch.

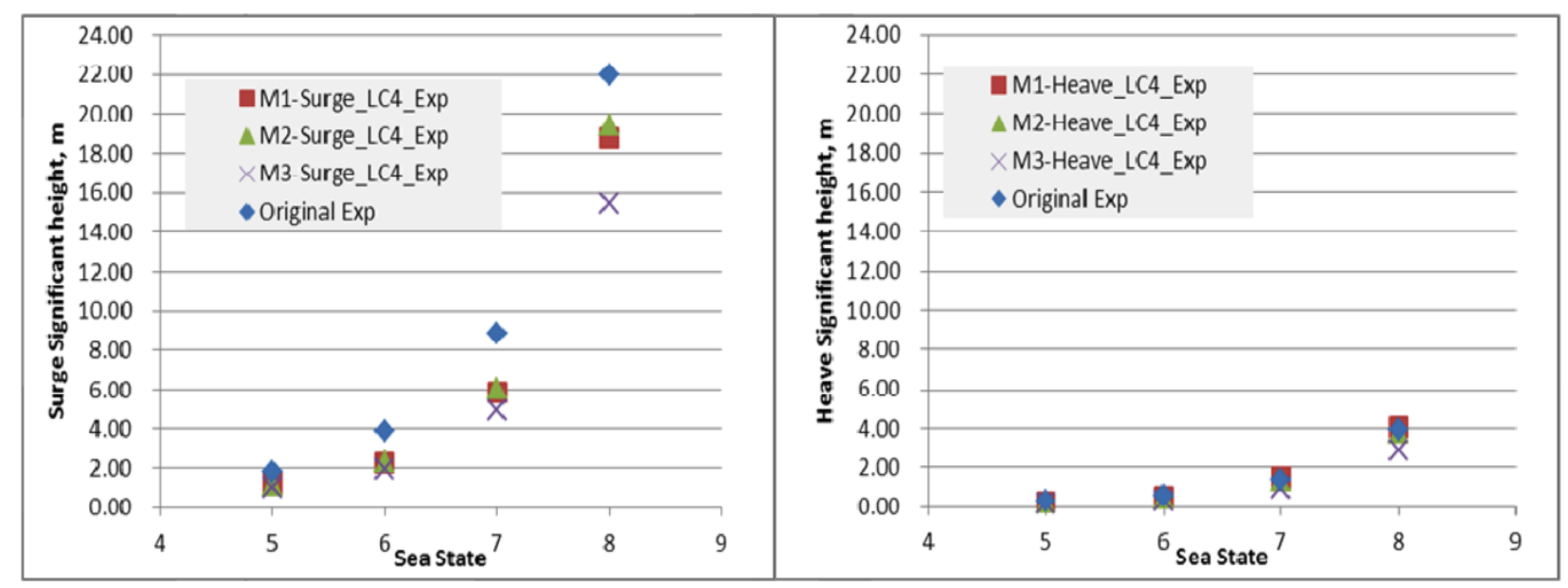

Fig. 14 Surge, heave significant height in LC04.

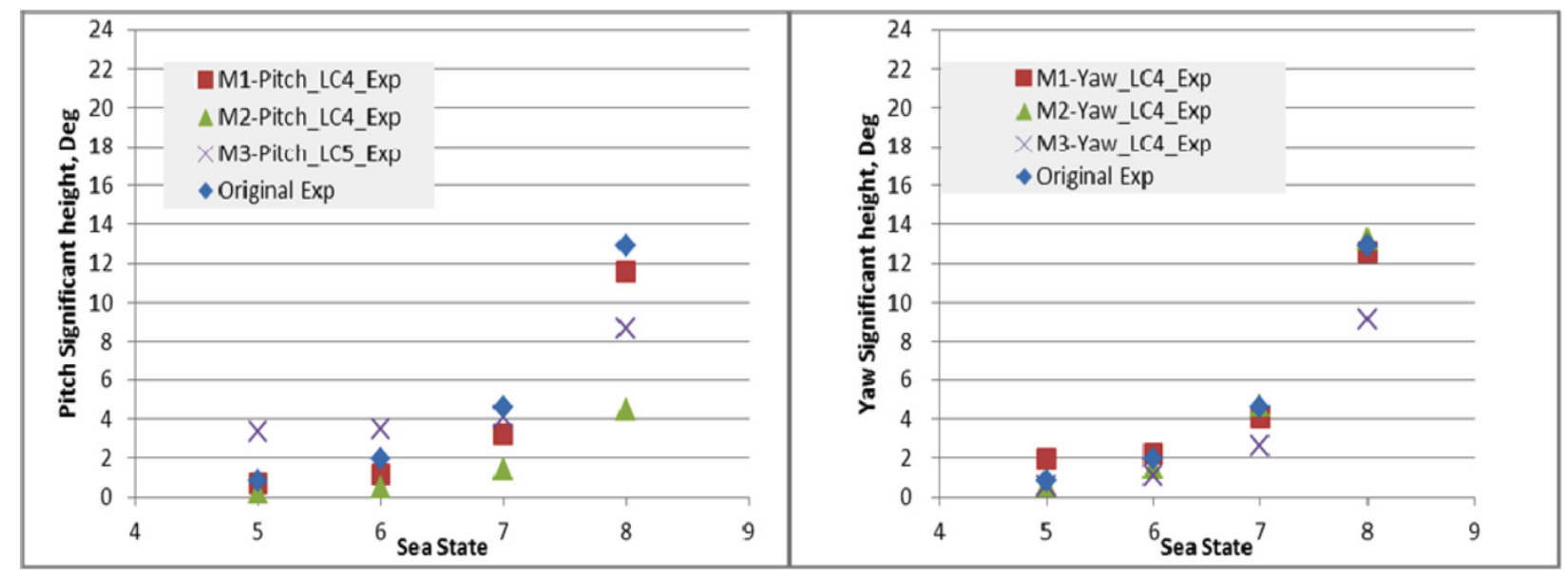

Fig. 15 Pitch and yaw significant height in LC04.

LC05 : Irregular waves, mean wind speed, parked rotor

As in LC04, M3 shows the smallest significant motion in all modes except in pitch (Figs. 16 and 17).

LC06 : Irregular waves, mean wind speed, rotating rotor

In surge, significant motions of M3 is larger than those of M1 and M2 in sea states 5 7 but smaller in sea state 8. In heave, pitch and yaw, M3 shows smaller significant motions than those of other models. 

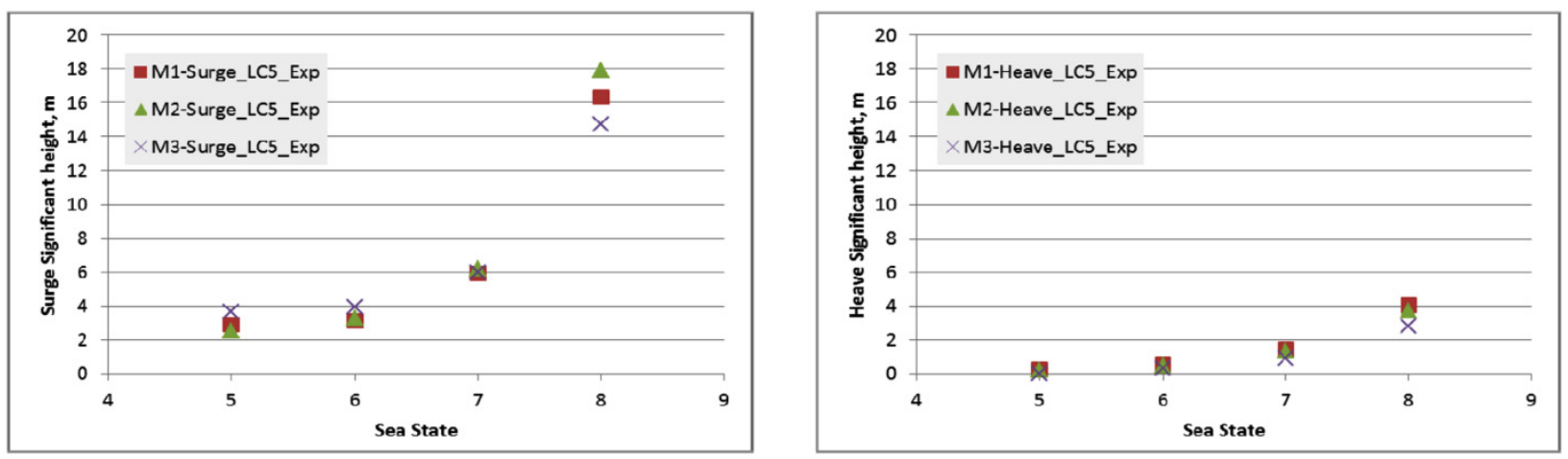

Fig. 16 Surge, heave significant motion in LC05.
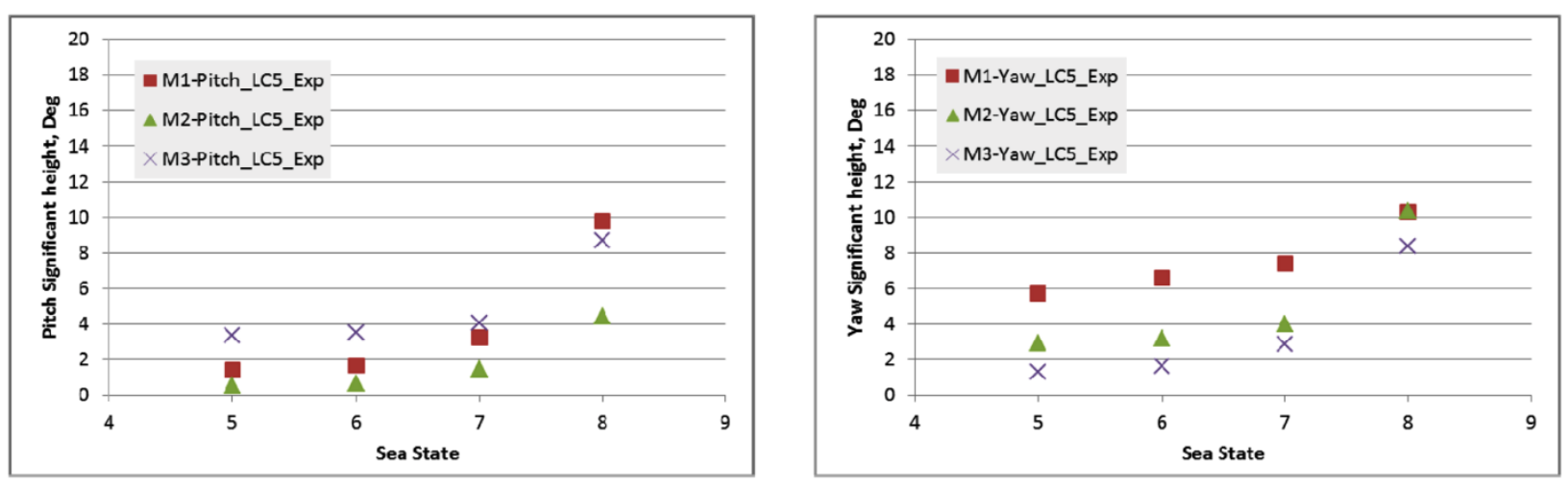

Fig. 17 Pitch and yaw significant motion in LC05.

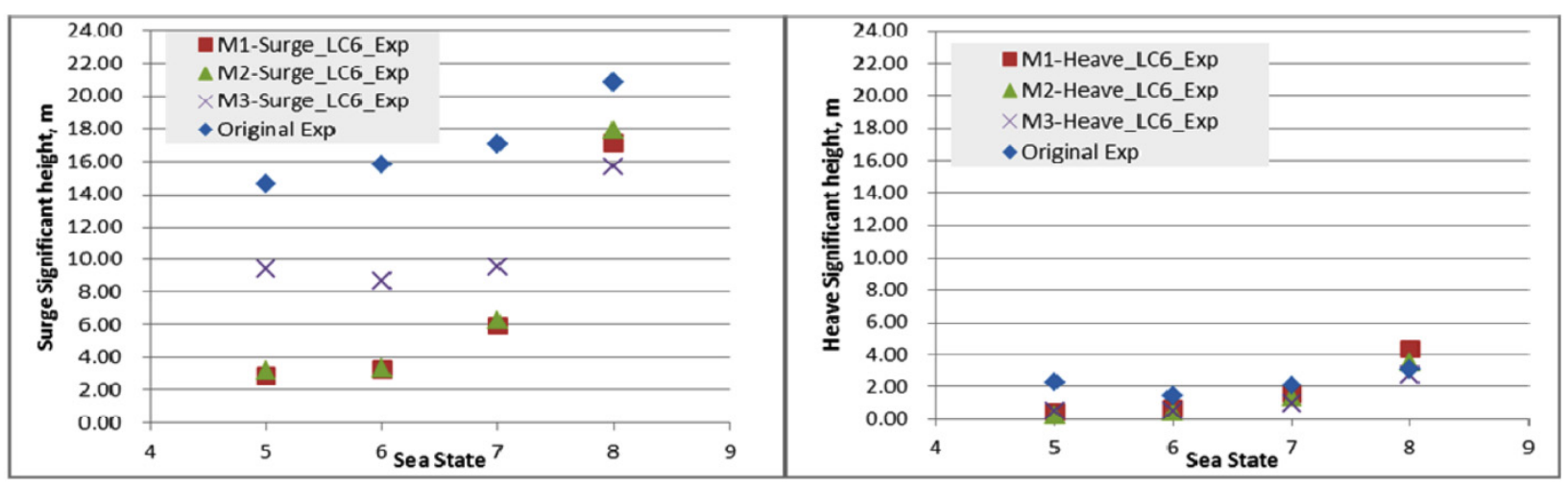

Fig. 18 Surge, heave significant motion in LC06.

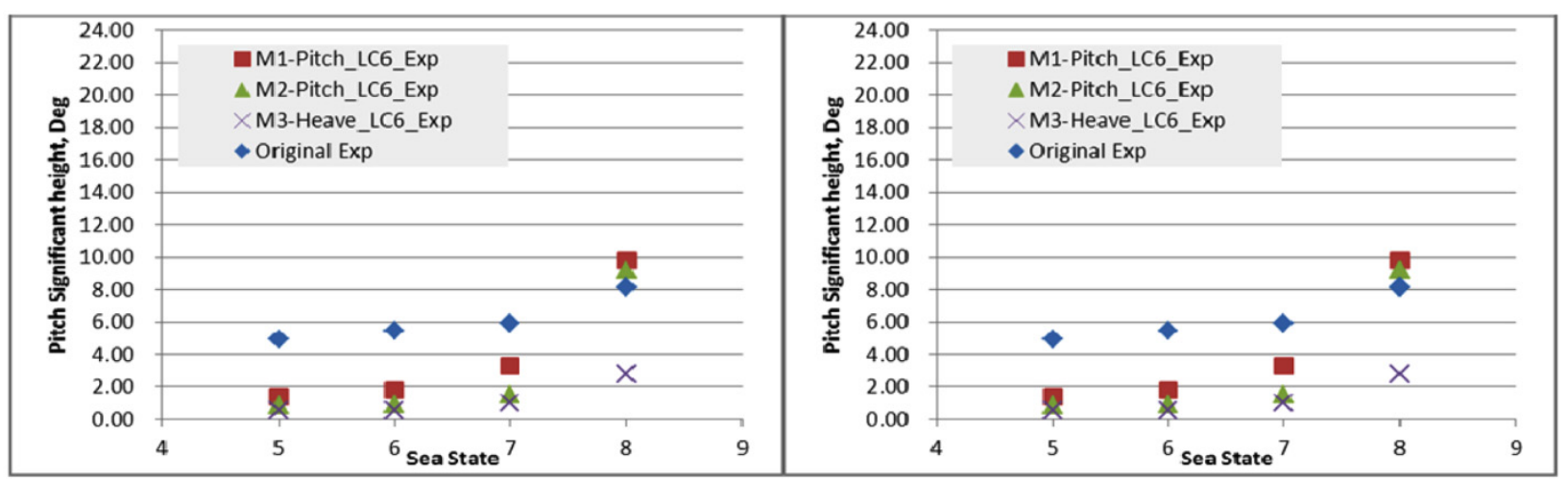

Fig. 19 Pitch and yaw significant motion in LC06. 


\section{CONCLUSIONS}

In this paper, scale model tests had been carried out in order to investigate the motion characteristics of three new floating offshore wind turbines, M1 M3. The load cases included effects of wave, wind and rotating rotor. The test results of M1 M3 were compared with those of the original OC3-Hywind.

The spar with ring cylinders causes water particles to be much more excited than without rings, that is, ring cylinders induce the increase in both added mass and damping and, in turn, both the increase in motion period and the decrease in motion height. As we expected, in most load cases, the responses of M1 M3 are smaller than those of the original OC3-Hywind.

- Regular waves : M3 shows the best performance in LC01 LC03.

- Irregular waves : M3 shows the best performance, except pitch in both LC04 and LC05 and except surge in LC06.

It is concluded that three new platforms, M1 M3 have better motion characteristics than the spar of the original OC3Hywind based on the model test results. Specially, M3 is recommended to a good platform in extreme weather conditions. In near future researches, low Reynolds effects on the Froude scaled rotor and wind will be investigated.

\section{ACKNOWLEDGEMENTS}

This work was supported by the Human Resources Development Program (No. 20124030200110) and the International Collaboration Program (No. 20128520020010) of the Korea Institute of Energy Technology Evaluation and Planning (KETEP) grant funded by the Korea government Ministry of Trade, Industry and Energy and also fully matched by the SOTOP project, University of Ulsan (UOU).

\section{REFERENCES}

Bulder, B., van Hees, M.T.h., Henderson, A.R., Huijsmans, R.H.M., Pierik, J.T.G., Snijders, E.J.B., Wijnants, G.H. and Wolf, M.J., 2002. Study to feasibility of and boundary conditions for floating offshore wind turbines. ECN, MARIN, TNO, TUD, MSC, Lagerway the Windmaster.

Jensen, J.J., Olsen, A.S. and Mansour, A.E., 2011. Extreme wave and wind response predictions. Ocean Engineering, 38 (17-18), pp.2244-2253.

Jonkman, J., Butterfield, S., Musial, W. and Scott, G., 2009. Definition of a 5-MW reference wind turbine for offshore system development. Technical Report NREL/TP-500-38060.

Jonkman, J., 2010. Definition of the floating system for phase IV of OC3. National Renewable Energy Laboratory (NREL), Technical Report NREL/TP-500-47535.

Kim, K.M., 2011. Experimental and numerical study on analysis of motion of floating offshore wind turbine. Master's thesis. University of Ulsan.

Lee, K.H., 2005. Responses of floating wind turbines to wind and wave excitation. MSc Thesis. University of Michigan.

Sclavounos, P.D., Tracy, C. and Lee, S.H., 2007. Floating offshore wind turbines: Responses in a seastate pareto optimal designs and economic assessment. Department of Mechanical Engineering, Massachusetts Institute of Technology.

Shin, H., 2011. Model test of the OC3-Hywind floating offshore wind turbine. Proceedings of 21st ISOPE. Maui, Hawaii, USA 19-24 June 2011.

Wang, L. and Sweetman, B., 2012. Simulation of large-amplitude motion of floating wind turbines using conservation of momentum. Ocean engineering, 42, pp.155-164.

Wayman, E., 2006. Coupled dynamics and economic analysis of floating wind turbine systems. M.S. Thesis. Massachusetts Institute of Technology.

Wayman, E., Sclavounos, P., Butterfield, S., Jonkman, J. and Musial, W., 2006. Coupled dynamic modeling of floating wind turbine systems. Offshore Technology Conference. Houston, Texas 1-4 May 2006. 